\title{
Antioxidant enzyme expression of mRNA and protein in the epididymis of finasteride-treated male rat offspring during postnatal development
}

Agnieszka Kolasa-Wołosiuk ${ }^{1}$, Maciej Tarnowski², Irena Baranowska-Bosiacka³, Dariusz Chlubek ${ }^{3}$, Barbara Wiszniewska ${ }^{1}$

\begin{abstract}
${ }^{1}$ Department of Histology and Embryology, Pomeranian Medical University, Szczecin, Poland

${ }^{2}$ Department of Physiology, Pomeranian Medical University, Szczecin, Poland

${ }^{3}$ Department of Biochemistry and Medical Chemistry, Pomeranian Medical University, Szczecin, Poland
\end{abstract}

Submitted: 8 December 2016

Accepted: 5 April 2017

Arch Med Sci 2019; 15 (3): 797-810

DOI: https://doi.org/10.5114/aoms.2017.68528

Copyright (c) 2017 Termedia \& Banach

\begin{abstract}
Introduction: We verify whether finasteride had a transgenerational effect on the epididymal expression of antioxidant enzymes, and the correlation between these enzymes and blood androgen concentrations in male offspring (F1:Fin) of females fertilized by finasteride-treated male rats.

Material and methods: The expression of CAT, SOD1, GPX5, GR on the mRNA and protein levels was evaluated in the epididymis at postnatal day (PND) 7 , 14, 21, 28 and 90. Levels of T and DHT were correlated with mRNA levels of enzymes by Spearman's rank correlation coefficient.

Results: A change in the levels of transcripts was noted in F1:Fin rats: CAT decreased at PND $28(p<0.01)$ and increased at PND $90(p<0.01)$; SOD 1 increased at PND $7(p<0.0001), 21(p<0.001), 90(p<0.0001)$ and decreased at 14 PND ( $p<0.01)$; GPX5 increased at PND 14 and $21(p<0.0001)$; GR decreased at PND 21 and $28(p<0.0001)$. Altered immunolocalization of enzymes within the epididymal epithelium was observed. Negative correlations between GPX5 mRNA with androgens (T, $p=0.0002$; DHT, $p=0.0009$ ) were visible in the control rats, and positive correlation between DHT and CAT mRNA $(p=0.03)$, in opposite to F1:Fin group were was negative for both androgens ( $\mathrm{T}, p=0.044$ and $\mathrm{DHT}, p=0.02$ ).

Conclusions: Finasteride treatment of adult male rats may cause changes in antioxidant defense system in the epididymis of their offspring, leading to improper ROS concentrations that can affect post-testicular sperm maturation.
\end{abstract}

Key words: SOD1, CAT, GPX5, GR, finasteride-treatment, epididymis.

\section{Introduction}

Mammalian spermatozoa progressively acquire motility and fertilizing abilities during their transport, protection and storage in the epididymis. Therefore, secretion and reabsorption carried out by the epithelium lining of the epididymis are crucial in creating an optimal fluid microenvironment for post-testicular sperm maturation [1-4]. During transit along the epididymis, spermatozoa are potentially exposed to the harmful effects of reactive oxygen species (ROS) [5, 6]. High concentrations of ROS in the

\author{
Corresponding author: \\ Agnieszka Kolasa-Wołosiuk PhD \\ Department of Histology \\ and Embryology \\ Pomeranian Medical \\ University \\ 72 Powstańców \\ Wielkopolskich St \\ 70-111 Szczecin, Poland \\ Phone: +48 914661677 \\ E-mail: agnieszka.kolasa@ \\ pum.edu.pl
}


epididymis are due to the high metabolic activity of epididymal epithelial cells and a rich network of blood vessels surrounding the ductus epididymis. Reactive oxygen species are locally generated as a by-product of prostaglandin [7] and steroid hormone [8] synthesis. Another direct source of ROS are spermatozoa [9]. Although small and controlled amounts of free radicals appear to be essential for normal physiological functioning of male germ cells (proper spermatozoa DNA condensation, sperm hyperactivation, motility, capacitation and acrosome reaction) [10, 11], the exposure of spermatozoa to a high level of ROS critically impairs their function $[5,6,12-15]$. Due to the ambiguous nature of ROS, maintaining their risk-benefit balance is crucial for correct sperm physiology. The concentrations of antioxidants, well known to play a crucial role in minimizing oxidative damage in spermatozoa [16, 17], are limited due to the low amount of cytoplasm [18] and so are inadequate for full spermatozoa self-protection [5, 15, 16, 19]. Therefore, increased attention has been paid to the epididymis as a supportive organ protecting male reproductive cells against oxidative stress [16], and a rich source of antioxidant enzymes, e.g. catalase (CAT), superoxide dismutase (SOD), and enzymes associated with glutathione peroxidation and reduction, such as glutathione peroxidase (GPX) [16, 20-28] and glutathione reductase (GR) [29].

Almost half of the expression of proteins synthesized in the epididymis is regulated by androgens [30], the transcriptional factors for genes encoding antioxidant enzymes such as GPX [24, 31-35], SOD and CAT [36]. In our previous study we showed that treatment with finasteride (an inhibitor of 5 -reductase type 2) in adult male rats influenced the patterns of E-SOD, GPX5, and $\mathrm{Cu} / \mathrm{ZnSOD}$ expression; that change was region-dependent and the expression was up- or down-regulated compared to control animals [37]. Recently, we also found that finasteride treatment of paternal rats resulted in altered serum and intratesticular levels of testosterone (T) and dihydrotestosterone (DHT) in their male offspring $[38,39]$. Consequently, it can be speculated that finasteride, a drug that modulates the activity of the key enzyme involved in the metabolism of T, can act in a similar fashion to endocrine disruptors (EDs), and can negatively influence epididymal protection of spermatozoa against oxidative stress. As demonstrated by Parlaktas et al. [40], the alterations in antioxidant ROS scavenging capacities of the variants of antioxidant enzymes could be related to prostate cancer development.

In the light of the above described data, the aim of the experiment was to analyze the influence of androgen imbalances on the antioxidant protective functions of the epididymis. In this work, special attention was paid to cytoplasmic Cu/Zn-superoxide dismutase (SOD1), secretory epididymal-specific glutathione peroxidase (GPX5), CAT and GR, because together they constitute the "enzymatic protective system" used by the cells to resist reactive oxygen species. We studied the expression of CAT, SOD1, GPX5 and GR mRNA, and the immunolocalization of the proteins of these enzymes within the epididymis during neonatal/postnatal maturation in immature 7-, 14-, 21-, 28- and mature 90-day-old rat offspring (F1:Fin) born from females fertilized by finasteride-treated males. Additionally, the levels of antioxidant enzyme transcripts were correlated with blood serum concentrations of $\mathrm{T}$ and DHT with respect to animal age.

\section{Material and methods}

\section{Animals}

The study was conducted on albino Wistar rats in accordance with Polish law and with the approval of the Local Ethics Committee for Scientific Experiments on Animals in Szczecin, Poland (Resolution no. 23/2010).

Parent generation FO produced male generation F1. Paternal rats in the F0:Fin group $(n=5)$ were treated with finasteride (Proscar, MSD, Cramlington, UK) in daily doses of $5 \mathrm{mg} / \mathrm{kg} / \mathrm{bw}$, according to our previous studies [41-43] and experiments by other researchers $[44,45]$. The period of finasteride treatment before mating lasted 56 days (this period changed morphology and function of the testis [41-43]). The filial generation was collected over a period of 5 months to avoid ageing of the parent generation. Male rats (F0:Fin) received finasteride up to the end of the experiment (for 4-5 months). Once a week, the animals were weighed and the finasteride doses adjusted.

\section{Generation of filial animals}

The control group of offspring (F1:Control, $n=25$ ) comprised male rats born from females fertilized by untreated control male rats. The experimental group of offspring (F1:Fin, $n=25)$ comprised male rats born from females fertilized by finasteride-treated male rats. The objective of the experiment was to sample the epididymis from both the treated and untreated offspring (F1) at 7, 14, 21,28 , and 90 postnatal days (PND) of life. Detailed information on the design of the animal treatment, mating, and collection of newborn offspring has been presented in our previous report [38]. After thiopental anesthesia (120 mg/kg bw, i.p., Biochemie $\mathrm{GmbH}$, Vienna, Austria), the epididymides were weighed and the right epididymides (5 animals per age group in the F1 generation) used for immunohistochemical (IHC) reactions, 
and the left epididymides frozen and used for qRT-PCR analysis.

\section{Quantitative real-time reverse transcription PCR (qRT-PCR) analysis}

Quantitative analysis of mRNA expression of Cat, Sod1, Gpx5 and Gsr was performed in a twostep reverse transcription PCR. Tissues were suspended in $600 \mu \mathrm{l}$ of RLT buffer and homogenized for $4 \mathrm{~min}$ on ice. Next, the sample was digested with proteinase $\mathrm{K}$ for $15 \mathrm{~min}$ at $55^{\circ} \mathrm{C}$ and isolated on spin columns according to the manufacturer's protocol. Total RNA was extracted from 50-100 mg tissue samples using an RNeasy Lipid Tissue Mini Kit (Qiagen, Germany). The RNA was then treated with DNase I (Qiagen) to eliminate genomic DNA contamination. All RNA isolated was quantified by spectrophotometry using a NanoDrop ND-1000 spectrophotometer (NanoDrop Technologies, USA) and the optical density 260/280 $\mathrm{nm}$ ratio was determined; the $260: 280$ ratios were 1.8-2.0. Next, cDNA was prepared from $1 \mu \mathrm{g}$ of total cellular RNA in a $20 \mu \mathrm{l}$ reaction volume, using a FirstStrand cDNA synthesis kit and oligo-dT primers (Fermentas, USA). Quantitative assessment of mRNA levels was performed by real-time RT-PCR using an ABI 7500 Fast instrument with Power SYBR Green PCR Master Mix reagent. Real-time conditions were as follows: $95^{\circ} \mathrm{C}(15 \mathrm{~s})$, 40 cycles at $95^{\circ} \mathrm{C}(15 \mathrm{~s})$, and $60^{\circ} \mathrm{C}(1 \mathrm{~min})$. Specificity assessment was done by performing melting curve analysis $\left(60^{\circ} \mathrm{C}\right.$ to $95^{\circ} \mathrm{C}$ in temperature ramp melting); only one PCR product was amplified under these conditions. Reaction mixtures contained $10 \mu \mathrm{l}$ of $2 \times$ SYBR Green supermix, $3 \mu$ l of primers (0.4 $\mu \mathrm{mol} / \mathrm{l}$ each), $2 \mu \mathrm{l}$ of cDNA template and $3 \mu \mathrm{l}$ of water. Each sample was analyzed in two technical replicates, and mean $C t$ values were used for further analysis. The relative quantity of a target, normalized to the endogenous control Gapdh gene and relative to a calibrator, is expressed as $2^{-\Delta \Delta C t}$ (-fold difference), where $C t$ is the threshold cycle, $\Delta C t=(C t$ of target genes $)-(C t$ of endogenous control gene), and $\Delta \Delta C t=(\Delta C t$ of samples for target gene) - ( $\Delta C t$ of calibrator for the target gene). The following primer pairs were used: for Cat (F: ATG GCT TTT GAC CCA AGC AA; R: CGG CCC TGG AGC ATC TTG T), for Sod1 (F: CAC TCT AAG AAA CAT GGC G; R: CTG AGA GTG AGA TCA CAC G), for Gpx5 (F: CAC CCC TCA GAG ACT GTG GT; R: TTG ACA GTG CTG ACA GGA GC) and for Gsr (F: GGA AGT CAA CGG GAA AAA GTT CAC TG; R: CAA TGTA ACC GGC ACC CAC AAT AAC). The primer sequences used in the study were obtained from the references [37, 46, 47], modified according to the sequence information obtained from the NCBI database, and were synthesized by Oligo.pl (IBB PAN, Poland).

\section{Immunohistochemistry}

The dissected epididymides were fixed in Bouin's fluid $(1 \mathrm{~h})$, and then washed with absolute ethanol (3 times over $3 \mathrm{~h}$ ), absolute ethanol with xylene $(1: 1)$ (twice over $1 \mathrm{~h}$ ) and xylene (3 times over $20 \mathrm{~min}$ ). Then, after $3 \mathrm{~h}$ of saturation of the tissues in liquid paraffin, the samples were embedded in paraffin blocks. Using a microtome (Microm HM340E), 3-5 $\mu \mathrm{m}$ serial sections were taken and placed on Polysine microscope slides (Thermo Scientific, UK; cat. no. J2800AMNZ). The sections of the epididymides were deparaffinized in xylene and rehydrated in decreasing concentrations of ethanol, and then used for immunohistochemical staining. In order to expose the epitopes, the sections were boiled twice in $10 \mathrm{nM}$ citrate buffer ( $\mathrm{pH} 6.0$ ) in a microwave oven (700 W for 4 and $3 \mathrm{~min}$ ). Once cooled and washed with PBS, the endogenous peroxidase was blocked using a $3 \%$ solution of perhydrol in methanol, and then the slides were incubated for $60 \mathrm{~min}$ at room temperature with primary antibodies against SOD-1 (Santa Cruz Biotechnology, sc-11407), CAT (Santa Cruz Biotechnology, sc-50508), GPX-5 (Santa Cruz Biotechnology, sc-376877) and GR (Santa Cruz Biotechnology, SC-133136). The final dilution of each antibody was $1: 300$. To visualize the antigen-antibody complex, a Dako LSAB+System-HRP was used (Code K0679; DakoCytomation, Glostrup, Denmark), based on the reaction of avidin-biotin-horseradish peroxidase with DAB as a chromogen, according to the included staining procedure instructions. Sections were washed in distilled $\mathrm{H}_{2} \mathrm{O}$ and counterstained with hematoxylin. For a negative control, specimens were processed in the absence of a primary antibody. Positive staining was determined microscopically (Leica DM5000B, Wetzlar, Germany) by visual identification of brown pigmentation.

\section{Statistical analysis}

The results of the qRT-PCR analysis were analyzed using Statistica 6.1 software (StatSoft, Kraków, Poland). The arithmetic means and SDs $(x \pm$ SD) were calculated for each parameter. Each variable was tested for normality with the Shapiro-Wilk test. As most of the results deviated from a normal distribution, a nonparametric test was used for further analysis. To assess the differences between the groups, the nonparametric Mann-Whitney $U$-test was used. A probability $p \leq 0.05$ was considered statistically significant. Correlations between the parameters were examined using Spearman's rank correlation coefficient $\left(r_{s}\right)$.

\section{Results}

Epididymis weight increased over time in the offspring in both the F1:Control $\left(r_{s}=+0.86\right.$, 
$p=0.0048)$ and the F1:Fin $\left(r_{s}=+0.94, p=0.0048\right)$ groups of rats, with significant differences in weight being observed between the groups at PND 14, 28 and 90 (Table I).

\section{Antioxidant enzymes' mRNA expression in epididymal homogenates}

Catalase: A decrease of CAT mRNA expression during aging was observed in both the F1:Control $\left(r_{s}=-0.64, p=0.000001\right)$ and F1:Fin groups $\left(r_{s}=\right.$ $-0.41, p=0.0036)$, as shown in Figure $1 \mathrm{~A}$. When comparing the F1:Fin and the F1:Control groups with respect to animal age (Figure $1 \mathrm{~B}$ ), during the first month of life the transcript level of CAT was statistically significantly lower in the F1:Fin group at PND 28 (more than 31\%); in the mature epididymis the level of CAT mRNA was statistically higher in the F1:Fin group (by about 61\%).

Superoxide dismutase 1: An increase of SOD1 mRNA level with age was observed in both the F1:Control $\left(r_{s}=+0.57, p=0.00005\right)$ and F1:Fin groups $\left(r_{s}=+0.45, p=0.000005\right)$. Figure $2 \mathrm{~A}$ shows the comparison of SOD mRNA expres- sion in each age group of the F1:Control and the $\mathrm{F} 1$ :Fin groups. Comparing the individual days of postnatal development of F1:Fin to the F1:Control group (Figure 2 B), differences in SOD1 mRNA expression were observed at PND 7, 14, 21 and 90 (increase of about $276 \%$, decreases of $37 \%$ and $71 \%$, and an increase over $114 \%$ for F1:Fin, respectively).

Glutathione peroxidase 5: During postnatal development, a very strong increase in GPX 5 mRNA expression was noted in both the F1:Control $\left(r_{s}=+0.80, p=0.0000001\right)$ and F1:Fin $\left(r_{s}=+0.89\right.$, $p=0.0000001)$ groups of rats, as shown in Figure $3 \mathrm{~A}$. Comparing the individual days of postnatal development of the F1:Fin group to the $\mathrm{F1}$ :Control group (Figure $3 \mathrm{~B}$ ), the differences in GPX5 mRNA expressions were statistically significantly higher in the F1:Fin group at PND 14 (2133\% increase) and PND 21 (335\% increase), with a very strong but not statistically significant decrease at PND 90 (62\%).

Glutathione reductase: There was no visible decreasing/increasing trend for GR mRNA with age (F1:Control: $r_{s}=-0.058, p=0.67$; F1:Fin:

Table I. Epididymis weight of rat offspring born from females fertilized by control or finasteride-treated male rats

\begin{tabular}{|lccc|}
\hline \multirow{2}{*}{ Age [PND] } & \multicolumn{2}{c|}{ Epididymis weight [mg] } & \multirow{2}{*}{$\%$ of change vs F1:Control } \\
\cline { 2 - 3 } & F1:Control & F1:Fin & \\
\hline 7 & $12.28 \pm 3.52$ & $12.48 \pm 1.86$ & $\uparrow 1.6 \%$ \\
\hline 14 & $17.15 \pm 4.68$ & $23.72 \pm 4.03^{\star * *}$ & $\uparrow 38.3 \%$ \\
\hline 21 & $29.57 \pm 4.09$ & $31.46 \pm 7.76$ & $\uparrow 6.4 \%$ \\
\hline 28 & $46.87 \pm 7.69$ & $39.83 \pm 5.96^{*}$ & $\downarrow 15.1 \%$ \\
\hline 90 & $492.7 \pm 31.34$ & $577.08 \pm 42.31^{\text {** }}$ & $\uparrow 17.1 \%$ \\
\hline
\end{tabular}

F1:Control, F1:Fin - rat offspring born from females fertilized by the control or finasteride-treated male rats, respectively. Values express arithmetic means $\pm S D(n=5$ per age group). Common superscripts within a row denote statistically significant differences between compared groups evaluated by the Mann-Whitney U-test: ${ }^{*} p<0.01,{ }^{* * *} p<0.0001$ ). The comparisons of F1:Fin vs F1:Control are expressed as percentages of decrease $(\downarrow)$ or increase $(\uparrow)$. PND - postnatal day.

A

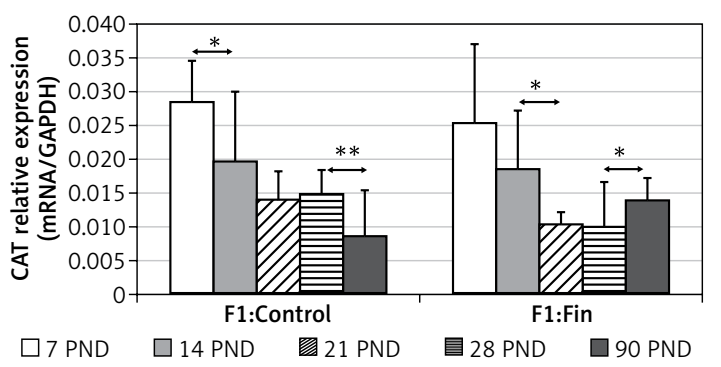

B

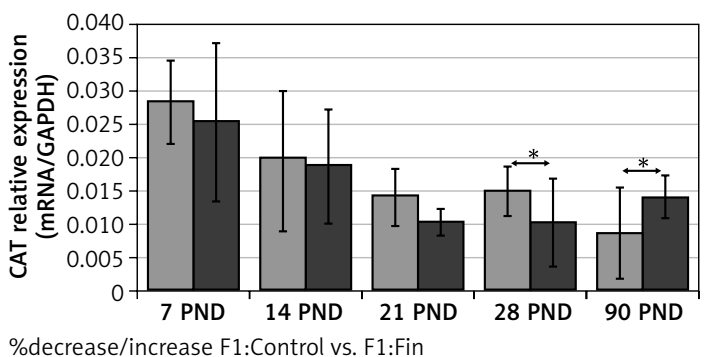

\%decrease/increase F1:Control vs. F1:Fin

$-10.7 \% \quad-3.6 \% \quad-25.9 \% \quad-31.3 \% \quad 60.7 \%$

$\square$ F1:Control $\quad \square$ F1:Fin

Figure 1. Representative of catalase mRNA levels (normalized to GAPDH) in homogenates of epididymal tissue of control offspring (F1:Control) and those born from females fertilized by finasteride-treated male rats (F1:Fin). Values are expressed as arithmetic means \pm SD; differences were evaluated using the Mann-Whitney $U$-test $(n=5$ per age group). A - Asterisks denote statistically significant differences between successive days of development (PND: postnatal day) in F1:Control and F1:Fin groups: ${ }^{*} p<0.01,{ }^{* *} p<0.001$. B - Asterisks denote statistically significant differences between F1:Control and F1:Fin on particular days of development (PND: postnatal day): ${ }^{*} p<0.01$ The diagram also shows the percentage of increase/decrease of CAT mRNA in F1:Fin in comparison to F1:Control 
A

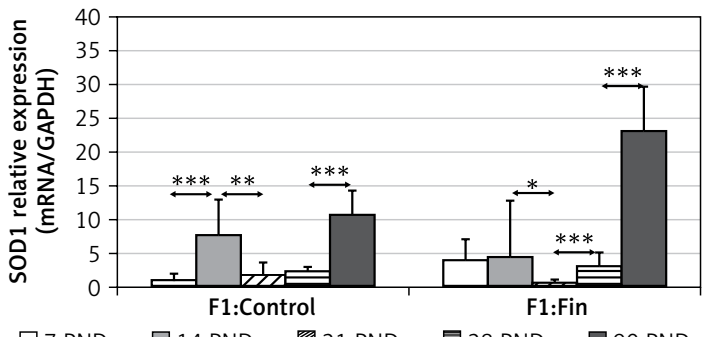

B

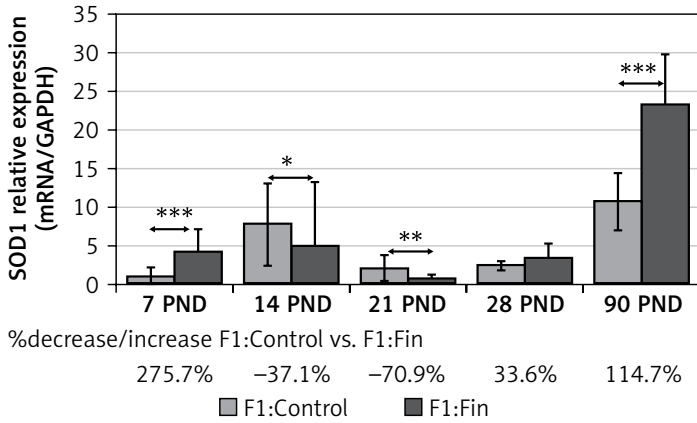

Figure 2. Representative of superoxide dismutase 1 mRNA levels (normalized to GAPDH) in homogenates of epididymal tissue of control offspring (F1:Control) and those born from females fertilized by finasteride-treated male rats (F1:Fin). Values are expressed as arithmetic means \pm SD; differences were evaluated using the Mann-Whitney $U$-test ( $n=5$ per age group). A - Asterisks denote statistically significant differences between successive days of development (PND: postnatal day) in F1:Control and F1:Fin groups: ${ }^{*} p<0.01,{ }^{* *} p<0.001,{ }^{* * *} p<0.0001$. B - Asterisks denote statistically significant differences between F1:Control and F1:Fin on particular days of development (PND: postnatal day): ${ }^{*} p<0.01,{ }^{* *} p<0.001,{ }^{* *} p<0.0001$. The diagram also shows the percentage of increase/ decrease of SOD1 mRNA in F1:Fin in comparison to F1:Control

A
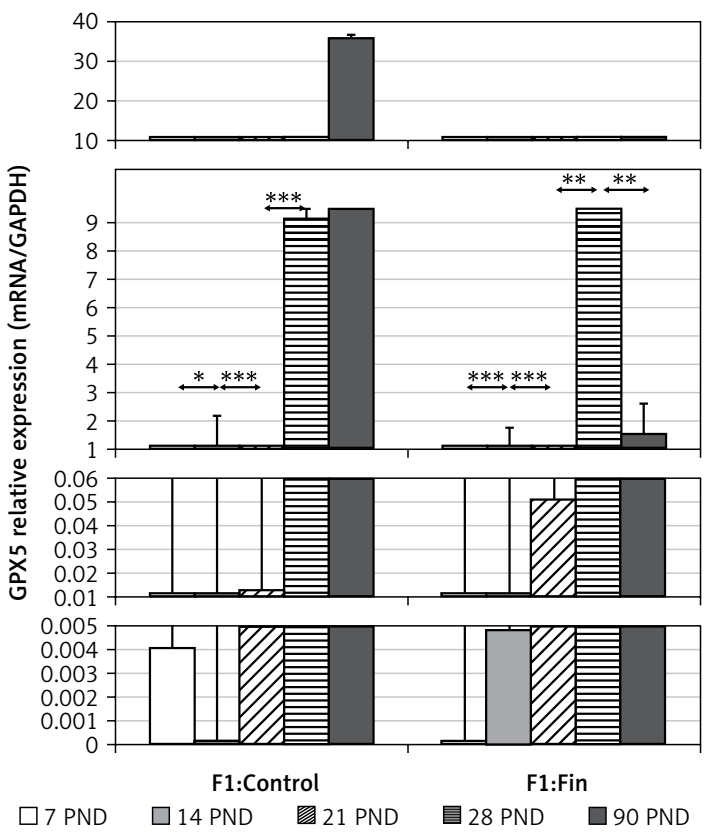

B

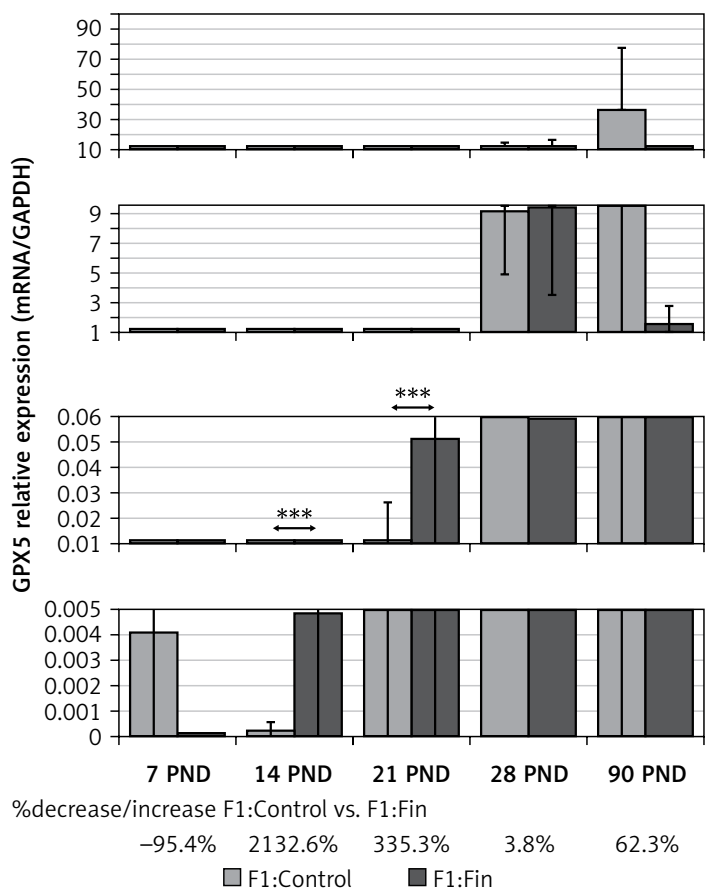

Figure 3. Representative of glutathione peroxidase 5 mRNA levels (normalized to GAPDH) in homogenates of epididymal tissue of control offspring (F1:Control) and those born from females fertilized by finasteride-treated male rats (F1:Fin). Values are expressed as arithmetic means \pm SD; differences were evaluated using the Mann-Whitney $U$-test ( $n=5$ per age group). A - Asterisks denote statistically significant differences between successive days of development (PND: postnatal day) in F1:Control and F1:Fin groups: ${ }^{*} p<0.01,{ }^{* *} p<0.001$, ${ }^{* * *} p<0.0001$. B - Asterisks denote statistically significant differences between F1:Control and F1:Fin on a particular day of development (PND: postnatal day): ${ }^{* *} p<0.001,{ }^{* * *} p<0.0001$. The diagram also shows the percentage of increase/decrease of GPX5 mRNA in F1:Fin in comparison to F1:Control

$\left.r_{s}=-0.027, p=0.85\right)$. However, there were statistically significant differences in transcript levels at different age group (Figure $4 \mathrm{~A}$ ). Comparing the individual days of postnatal development of the F1:Fin group to the F1:Control group (Figure $4 \mathrm{~B}$ ), a statistically significant decrease in GR mRNA expression was observed at both PND 21 and 28 (74\% and 10\%, respectively).

\section{Immunohistochemical expression and localization of antioxidant enzymes in the epididymis}

The gradient of staining intensity is described according to the adopted scale in Table II.

Catalase: The immunoexpression of CAT in the control rats during the first month of postnatal 
A

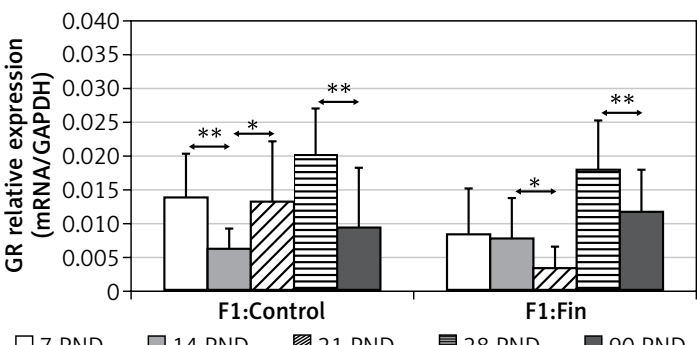

B

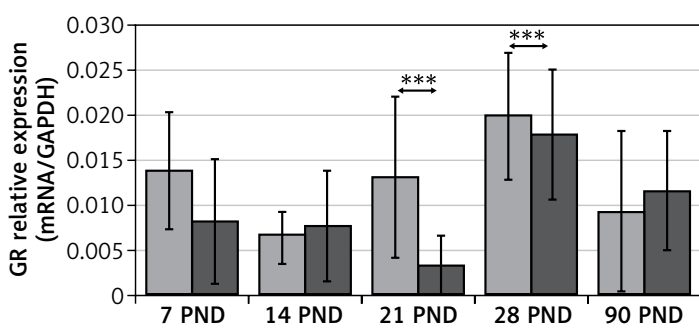

\%decrease/increase F1:Control vs. F1:Fin

$$
\begin{array}{cccc}
-39.7 \% \quad 2.9 \% & -74.5 \% \quad 10.3 \% & 22.7 \% \\
\square \text { F1:Control } & \square \text { F1:Fin }
\end{array}
$$

Figure 4. Representative of glutathione reductase mRNA levels (normalized to GAPDH) in homogenates of epididymal tissue of control offspring (F1:Control) and those born from females fertilized by finasteride-treated male rats (F1:Fin). Values are expressed as arithmetic means \pm SD; differences were evaluated using the Mann-Whitney $U$-test ( $n=5$ per age group). A - Asterisks denote statistically significant differences between successive days of development (PND: postnatal day) in F1:Control and F1:Fin groups: ${ }^{*} p<0.01,{ }^{* *} p<0.001$. B - Asterisks denote statistically significant differences between F1:Control and F1:Fin on a particular day of development (PND: postnatal day): ${ }^{* * *} p<0.0001$. The diagram also shows the percentage of increase/decrease of GR mRNA in F1:Fin in comparison to F1:Control

life (Figures 5 A-D) gradually decreased and had a more apical localization (red arrows) or granular across the cytoplasm, in contrast to the mature epididymis (Figure $5 \mathrm{E}$ ), which exhibited an almost negative but basal (black arrows) or diffuse pattern across the whole cytoplasm (white asterisk), with many epithelial cells immunonegative (blue arrow).

In the F1:Fin group of rats an apical localization (red arrows) of catalase was visible during the first 3 weeks of development (Figures $5 \mathrm{~F}-\mathrm{H}$ ), taking place more basally (black arrows) in epididymal epithelial cells at PND 28 (Figure $5 \mathrm{I}$ ) and PND 90 (Figures $5 \mathrm{~J}$ ). In immature epididymis of F1:Fin rats (Figures $5 \mathrm{~F}-\mathrm{I}$ ), CAT expression was lower than in the control (Figures $5 \mathrm{~A}-\mathrm{D}$ ), in contrast to the mature tissues, where it was higher (Figure $5 \mathrm{~J}$ ).

Superoxide dismutase 1: In the F1:Control group the SOD1 staining intensity had a fluctuating pattern - moderate during the first, second and fourth week of life (Figures 6 A, B, D), weak at PND 21 (Figure $6 \mathrm{C}$ ), and highest in the mature epididymis (Figure $6 \mathrm{E}$ ). In immature epididymis (Figures 6 A-D) SOD1 was mainly localized in api- cal regions of epithelial cells (red arrows); at PND 90 (Figure $6 \mathrm{E}$ ) most cells had the whole cytoplasm immunopositive (white asterisk), while some were immunonegative (blue arrow).

In the F1:Fin groups, the intensity and localization of SOD1 also depended on age. Intensity had the lowest level at PND 21 (Figure $6 \mathrm{H}$ ); apical localization (red arrows) was observed during the pre-pubertal period (Figures $6 \mathrm{~F}-\mathrm{H}$ ); and in the mature epididymis (Figure $6 \mathrm{~J}$ ) the majority of epithelial cells had a moderate, diffused (white asterisk) or strong perinuclear (black arrows) SOD1 reaction.

Glutathione peroxidase 5: Immunoexpression of GPX5 during the first 3 weeks of postnatal life was very weak in both the F1:Control (Figures $7 \mathrm{~A}-\mathrm{C}$ ) and $\mathrm{F} 1$ :Fin (Figures $7 \mathrm{~F}-\mathrm{H}$ ) groups of rats. At PND 28 in the F1:Control rats (Figure $7 \mathrm{D}$ ), some epithelial cells expressed GPX5 across the cytoplasm (white asterisks) while others had an immunopositive apex (red arrows). GPX5 immunoexpression in the epididymis of adult animals (Figure $7 \mathrm{E}$ ) became very strong and was located within some cell cytoplasm (white asterisk), apical areas of cells (red arrow) or in stereocilia (pink

\begin{tabular}{|c|c|c|c|c|c|c|c|c|}
\hline \multirow{2}{*}{$\begin{array}{l}\text { Age } \\
\text { [PND] }\end{array}$} & \multicolumn{2}{|c|}{ CAT } & \multicolumn{2}{|c|}{ SOD 1} & \multicolumn{2}{|c|}{ GPX 5} & \multicolumn{2}{|c|}{ GR } \\
\hline & F1:Control & F1:Fin & F1:Control & F1:Fin & F1:Control & F1:Fin & F1:Control & F1:Fin \\
\hline 7 & +++ & ++ & ++ & ++ & $+/-$ & $+/-$ & ++ & + \\
\hline 14 & ++ & ++ & ++ & ++ & $+/-$ & $+/-$ & ++ & ++ \\
\hline 21 & + & + & + & $+/-$ & + & + & + & $+/-$ \\
\hline 28 & + & + & ++ & ++ & ++ & ++ & ++ & + \\
\hline 90 & $+/-$ & ++ & +++ & +++ & +++ & ++ & $+/-$ & + \\
\hline
\end{tabular}

Table II. Antioxidant immunoreactivity based on visual examination of intensity

Immunoreactivity of cells: negative (-), almost negative (+/-), weak positive (+), moderate positive (++); strong positive (+++). F1:Control, F1:Fin - rat offspring born from females fertilized by the control or finasteride-treated male rats, respectively. PND - postnatal day. 


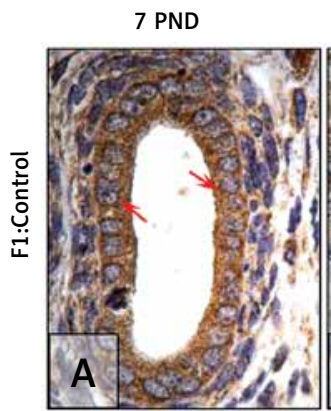

14 PND

21 PND

28 PND

90 PND
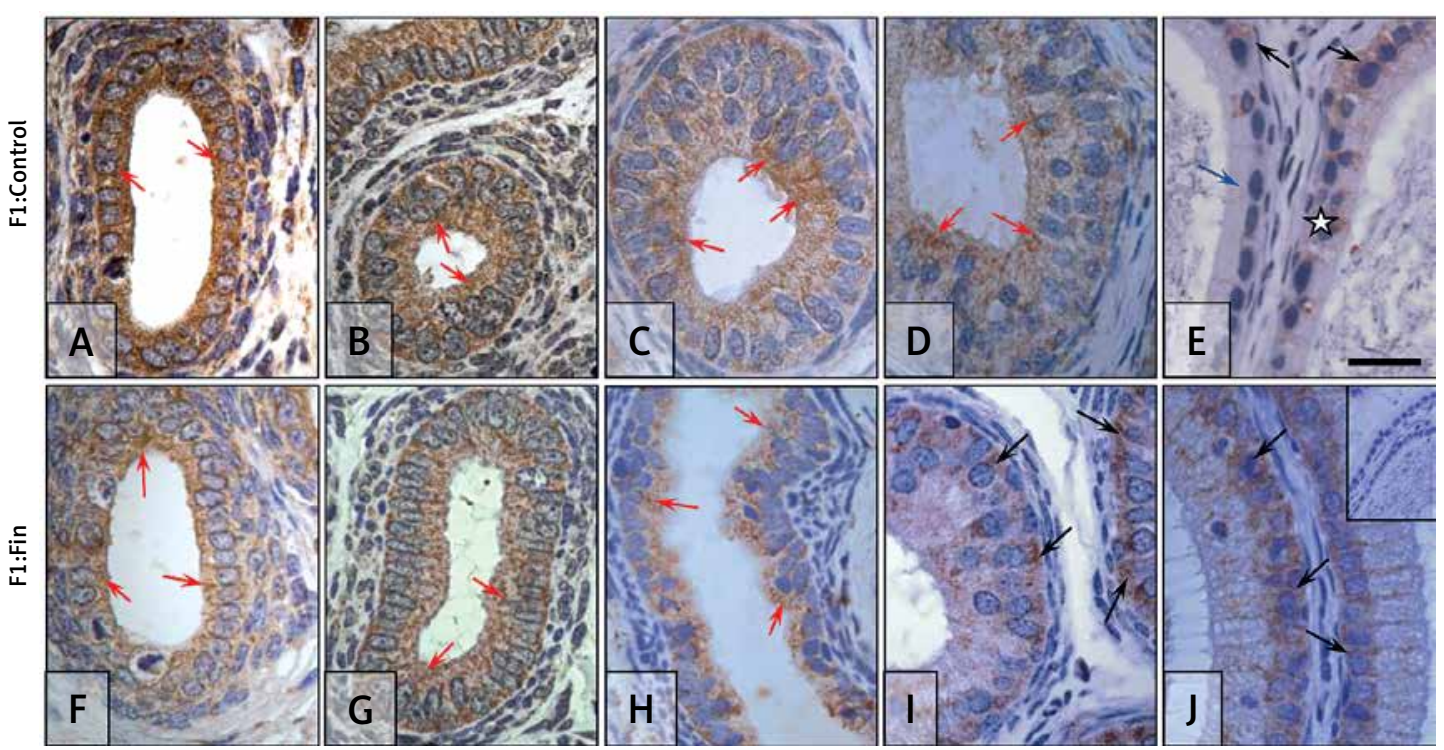

Figure 5. Immunoexpression of catalase within the epididymis of rat offspring born from females fertilized by control (A-E) and finasteride-administered (F-J) male rats. Well-visible immunoexpression of CAT in epididymal epithelial cells: during the first month of development (A-D, F-I) mainly in the supranuclear, apical region of cells; after reaching maturity $(E, J)$, mainly basal localization. Objective magnification: $A-J \times 100$, scale bar: $20 \mu \mathrm{m}$. In the upper right corner of the J photograph the negative control of IHC reaction. F1:Control, F1:Fin - rat offspring born from females fertilized by the control or finasteride-treated male rats, respectively $(n=5$ per age group); PND - postnatal day; red arrows - apical immunoexpression of enzyme; black arrows - basal/perinuclear immunoexpression of enzyme; blue arrow - immunonegative cell; white asterisk - diffuse/cytoplasmic immunoexpression

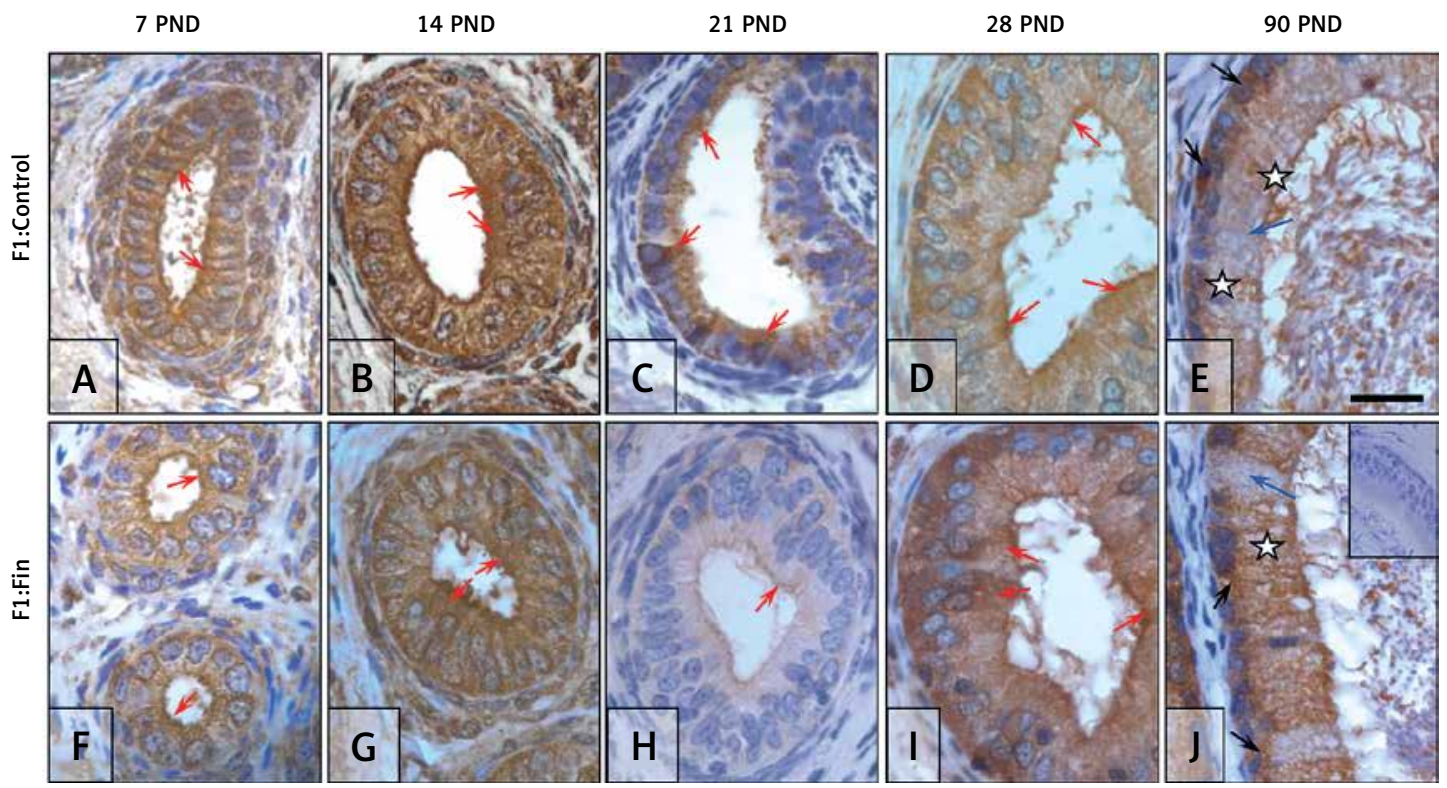

Figure 6. Immunoexpression of superoxide dismutase 1 within the epididymis of rat offspring born from females fertilized by control $(\mathrm{A}-\mathrm{E})$ and finasteride-administered $(\mathrm{F}-\mathrm{J})$ male rats. Strong, homogeneous immunolocation of SOD1 in epididymal epithelial cells during first 2 weeks of life (A-B, F-G); quenched but not different in respect of location and type of cells immunoexpression on $21^{\text {st }}$ and $28^{\text {th }}$ day of life $(C-D, H-I)$; diffuse cytoplasmic or perinuclear expression during maturity (E, J). Objective magnification: A-J 100x, scale bar: $20 \mu \mathrm{m}$. In the upper right corner of the J photograph the negative control of IHC reaction. F1:Control, F1:Fin - rat offspring born from females fertilized by the control or finasteride-treated male rats, respectively ( $n=5$ per age group); PND - postnatal day; red arrows - apical immunoexpression of enzyme; black arrows - basal/perinuclear immunoexpression of enzyme; blue arrow - immunonegative cell; white asterisk - diffuse/cytoplasmic immunoexpression

arrows); spermatozoa (yellow asterisk) located within the lumen of ductus epididymis were also GPX5-reactive.
The same mode of immunoexpression and immunolocalization was observed in F1:Fin rats (Figures $7 \mathrm{~F}-\mathrm{J}$ ), but signaling in mature F1:Fin rats 


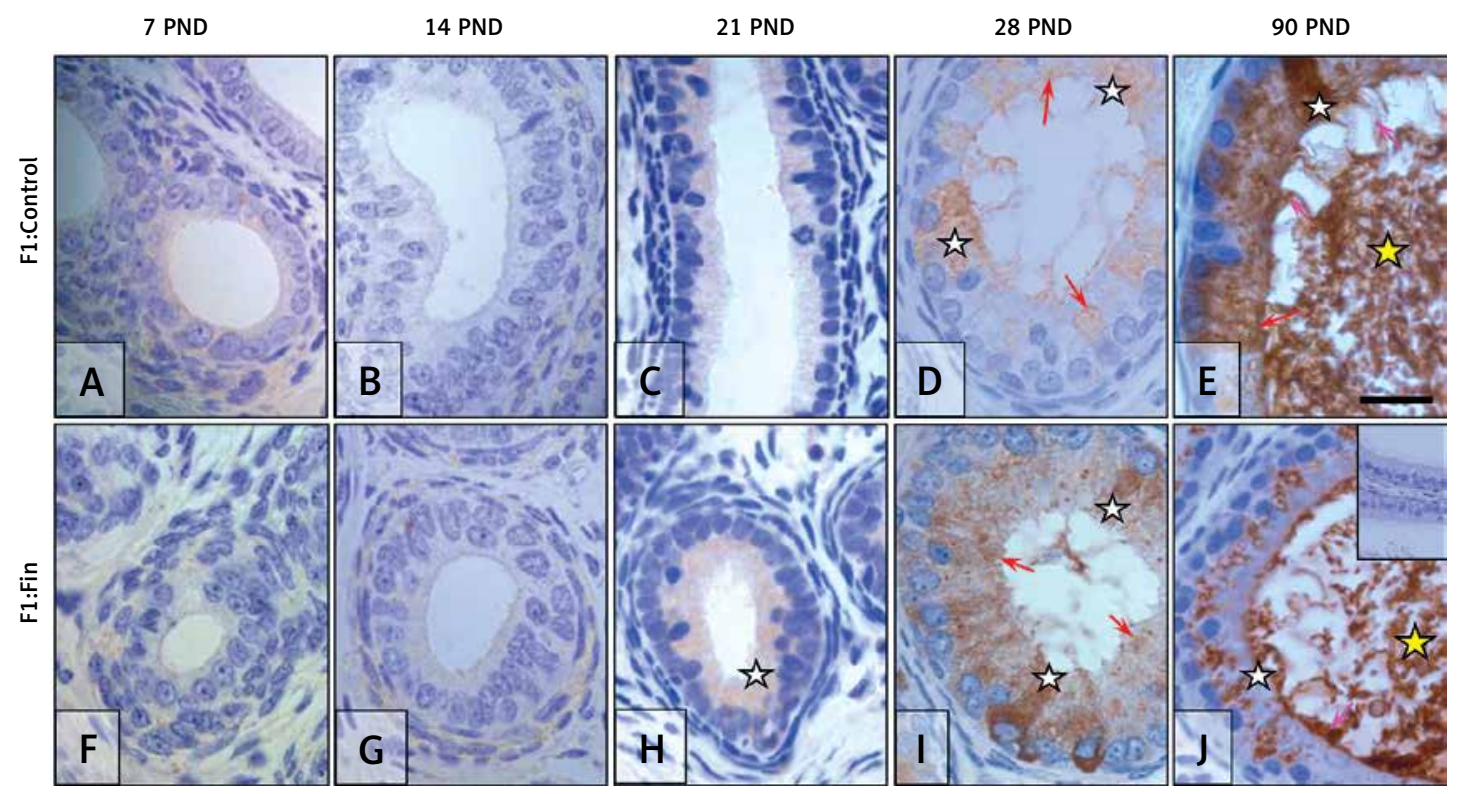

Figure 7. Immunoexpression of glutathione peroxidase 5 within the epididymis of rat offspring born from females fertilized by control (A-E) and finasteride-administered ( $\mathrm{F}-\mathrm{J})$ male rats. Almost invisible, very weak GPX 5 expression in epididymal epithelial cells during first three weeks of life (A-C, $\mathbf{F}-\mathbf{H})$; the severity of the reaction in the individual cells on $28^{\text {th }}$ day of life (D, I); and during maturity GPX5 become stronger mainly in F1:Control rats $(\mathrm{E})$. Objective magnification: A-J 100x, scale bar: $20 \mu \mathrm{m}$. In the upper right corner of the J photograph the negative control of IHC reaction. F1:Control, F1:Fin - rat offspring born from females fertilized by the control or finasteride-treated male rats, respectively ( $n=5$ per age group); PND - postnatal day; red arrows - apical immunoexpression of enzyme; pink arrows - immunopositive stereocilia; white asterisk - diffuse/cytoplasmic immunoexpression; yellow asterisk - immunopositive spermatozoa

(Figure $7 \mathrm{~J}$ ) was weaker than in F1:Control (Figure 7 E) rats.

Glutathione reductase: The expression of GR in epididymal epithelial cells during the first 3 weeks in the F1:Control group (Figures $8 \mathrm{~A}-\mathrm{C}$ ) displayed a cytoplasmic diffuse pattern (white asterisks) with a stronger indication in the apical part of the cells (red arrows). At PND 28 (Figure $8 \mathrm{D}), \mathrm{GR}$ exhibited a strong diffuse expression (white asterisk) with tight indication around the nucleus (black arrows). Within the mature epididymis (Figure 8 E) GR expression was much lower than in the immature cells (Figures 8 A-D) and mainly located basally, around the cell nucleus (black arrows), but some cells were immunonegative (blue arrows).

In the F1:Fin group, the intensity and localization of GR depended on age. During the first 2 weeks of life (Figures 8 F, G) GR was expressed across the cell cytoplasm (white asterisk), in particular at the cell apex (red arrows). At PND 21 immunostaining in the F1:Fin group became low (Figure $8 \mathrm{H}$ ); 1 week later (Figure $8 \mathrm{I}$ ) it became moderate and diffuse (white asterisk) and some cells had apical (red arrows) or perinuclear (black arrows) localization. At PND 90 (Figure $8 \mathrm{~J}$ ), some epithelial cells had a moderate GR-positive reaction in the nuclear (black arrows) or apical (red arrow) region of the cell. Staining intensity in immature epididymis in the F1:Fin group (Figures $8 \mathrm{~F}-\mathrm{I}$ ) was lower than in the F1:Control rats
(Figures $8 \mathrm{~A}-\mathrm{D}$ ), but in the mature rats (Figure $8 \mathrm{~J}$ ) GR-immunoexpression in some cells was higher than in the control (Figure $8 \mathrm{E}$ ).

\section{Correlation of mRNAs of antioxidant enzymes with serum $\mathrm{T}$ and DHT}

Table III shows the blood serum level of androgens presented in our previous study [38], which was used to make correlations with the levels of antioxidant enzyme mRNA.

There were statistically significant correlations between the concentrations of androgens and mRNA expression for CAT and GPX5 only (Table IV).

With respect to age in the F1:Control group a moderate positive correlation between DHT and CAT mRNA was observed. In contrast, in the F1:Fin group a moderate negative correlation was observed for both androgens ( $T$ and $\mathrm{DHT}$ ) and CAT mRNA. Age-dependent strong negative correlations between GPX5 mRNA and both androgens (T, DHT) were observed just in the F1:Control group.

\section{Discussion}

The functions of the epididymis and thus post-testicular spermatozoa maturation are androgen-dependent [48-50]. To acquire a proper physiology the male gametes require interaction with the epididymal luminal fluid [51], rich in antioxidant enzymes [16]. Nevertheless, a physio- 


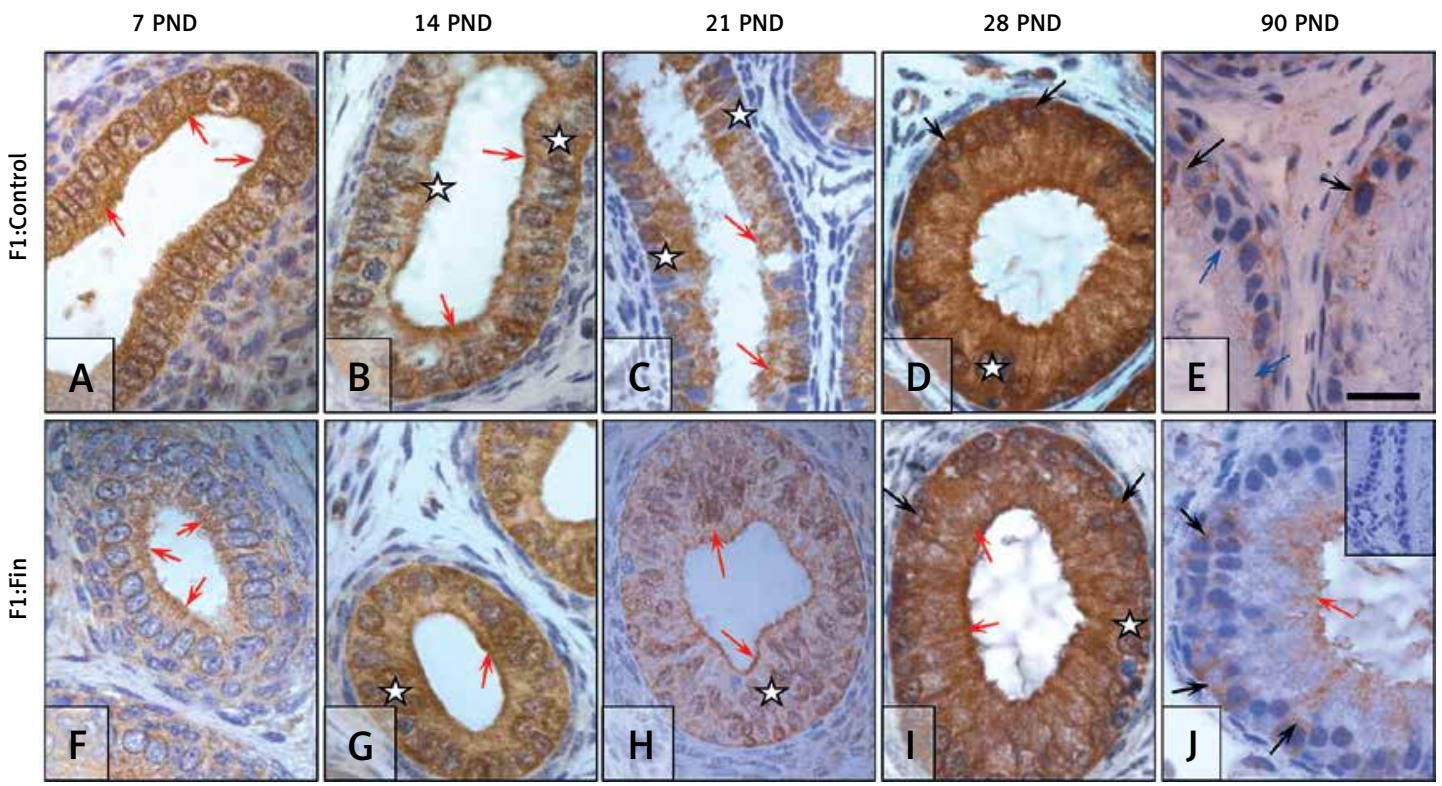

Figure 8. Immunoexpression of glutathione reductase within the epididymis of rat offspring born from females fertilized by control (A-E) and finasteride-administered ( $\mathrm{F}-\mathrm{J})$ male rats. During the first 2 weeks of development the localization and intensity of GR expression is comparable in F1:Control and F1:Fin (A-B, F-G); much lower relative to control (C), almost invisible immunoreaction in PND 28 F1:Fin $(H)$; strong, diffuse pattern of IHC in PND 28 F1:Control (D) and lower in PND 28 F1:Fin (I); during puberty (E, J) the expression became much lower than in the prepubertal period. Objective magnification: A-J 100x, scale bar: $20 \mu \mathrm{m}$. In the upper right corner of the J photograph the negative control of IHC reaction. F1:Control, F1:Fin - rat offspring born from females fertilized by the control or finasteride-treated male rats, respectively ( $n=5$ per age group); PND - postnatal day; red arrows apical immunoexpression of enzyme; black arrows - basal/perinuclear immunoexpression of enzyme; blue arrows - immunonegative cells; white asterisk - diffuse/cytoplasmic immunoexpression

Table III. Testosterone and dihydrotestosterone concentrations in blood serum of rat offspring born from females fertilized by control (F1:Control) or finasteride-treated (F1:Fin) male rats (published in [38])

\begin{tabular}{|lcccc|}
\hline $\begin{array}{l}\text { Age } \\
{[\text { PND }]}\end{array}$ & \multicolumn{2}{c}{ T $[\mathrm{ng} / \mathrm{mg}]$} & \multicolumn{2}{c|}{ DHT $[\mathrm{pg} / \mathrm{mg}]$} \\
\cline { 2 - 5 } & F1:Control & F1:Fin & F1:Control & F1:Fin \\
\hline 14 & $3.91 \pm 0.16$ & $1.68 \pm 1.03^{* *}$ & $1608.65 \pm 75.24$ & $774.81 \pm 46.07^{\star *}$ \\
\hline 21 & $2.62 \pm 0.29$ & $2.67 \pm 0.21$ & $1096.51 \pm 137.78$ & $1053.89 \pm 71.04$ \\
\hline 22 & $2.90 \pm 0.51$ & $3.46 \pm 0.59$ & $1189.19 \pm 261.44$ & $1577.09 \pm 189.19^{* *}$ \\
\hline 28 & $2.86 \pm 0.15$ & $3.52 \pm 0.52^{\star *}$ & $1322.47 \pm 41.01$ & $1482.14 \pm 26.40$ \\
\hline 90 & $0.46 \pm 0.11$ & $0.92 \pm 0.61^{* * *}$ & $443.64 \pm 180.51$ & $280.60 \pm 25.83^{* *}$ \\
\hline
\end{tabular}

F1:Control, F1:Fin - rat offspring born from females fertilized by the control or finasteride-treated male rats, respectively, PND - postnatal day. Values are expressed as arithmetic means $\pm S D\left(n=5\right.$ per age group) evaluated by the Mann-Whitney $U$-test. ${ }^{* *} p<0.001$, ${ }^{* * *} p<0.0001$.

Table IV. Correlation between serum androgens (T, DHT) and mRNAs for catalase, superoxide dismutase 1, glutathione peroxidase 5 and glutathione reductase in epididymal homogenates of male control rats offspring (F1:Control) and finasteride-treated male rat offspring (F1:Fin)

\begin{tabular}{|lcccc|}
\hline Parameter & \multicolumn{2}{c}{ F1:Control } & \multicolumn{2}{c|}{ F1:Fin } \\
\cline { 2 - 5 } & T & DHT & T & DHT \\
\hline CAT & $r_{s}=+0.34$ & $r_{s}=+0.45$ & $r_{s}=-0.41$ & $r_{s}=-0.46$ \\
& $p=0.105$ & ${ }^{*} p=0.03$ & ${ }^{*} p=0.044$ & ${ }^{*} p=0.02$ \\
\hline SOD1 & $r_{s}=-0.28$ & $r_{s}=-0.20$ & $r_{s}=-0.31$ & $r_{s}=-0.33$ \\
& $p=0.177$ & $p=0.353$ & $p=0.137$ & $p=0.122$ \\
\hline GPX5 & $r_{s}=-0.69$ & $r_{s}=-0.63$ & $r_{s}=+0.031$ & $r_{s}=+0.213$ \\
& $* *=0.0002$ & $* * p=0.0009$ & $p=0.884$ & $p=0.328$ \\
\hline GR & $r_{s}=+0.051$ & $r_{s}=-0.176$ & $r_{s}=-0.002$ & $r_{s}=-0.061$ \\
& $p=0.766$ & $p=0.302$ & $p=0.991$ & $p=0.746$ \\
\hline
\end{tabular}

Values expressed as Spearman's rank coefficient $(r)$ with statistically significant probability $p \leq 0.05$. 
logical level of ROS is necessary for suitable DNA condensation, sperm hyperactivation, forward motility, capacitation and acrosome reaction [1113]. Consequently, spermatozoa have to face the so-called 'oxygen paradox' $[11,52,53]$ and any agents that disturb the epididymal functions may also affect the correct and required levels of antioxidant enzymes [13].

\section{Weight of epididymides}

In this study we observed differences in the weight of the epididymides of rats born from females fertilized by finasteride-treated male rats in comparison to the F1:Control animals. Due to the fact that finasteride, as an inhibitor of $5 \alpha$-reductase, altered androgen homeostasis, as shown in a previous work [38], it could be considered an endocrine disruptor (ED). A reduction in the size of the epididymides in male offspring was induced by the treatment of mice during pregnancy with bisphenol A (BSA; ED with estrogenic activity) [54]. The organ's mass has also been reduced by the postnatal influence of dioxin [55], nonylphenol [56], BSA [57], lindane (an insecticide with estrogenic and antiestrogenic properties) [58], methoxychlor (a pesticide with estrogenic/antiandrogenic activity) [59] and atrazine (a herbicide that has endocrine-disrupting effects on the reproductive system) [60]. In this study, the weights of the epididymides from the F1:Fin rats were higher than the control animals of the same age (apart from PND 28 - similar testis weight [38]), probably because of a correlation with total body weight or the same weight fluctuation differences in the testes [38]. These observations may be associated with the modulation of adipose tissue metabolism by androgens [61], and therefore could be affected by changes in the T/DHT ratio observed in our experiment.

\section{Age-related changes in expression of antioxidant enzymes in the epididymis and consequences}

The results of this study confirm the changes in antioxidant enzyme expression of mRNA and proteins during postnatal maturation, being different in immature rats (PND 7, 14, 21, 28) than in mature animals (PND 90), in agreement with other reports [62] that demonstrated changes in antioxidant enzymes' (GPX, GR, CAT, SOD) activity in male reproductive tissues (such as the cauda epididymidis) in young (4-month-old) rats when compared to older (21-month-old) rats. Some authors [16] consider CAT one of the most controversial enzymes within the epididymis, such as when CAT mRNA expression is extremely low, undermining its potential role as a major antiox- idant in the tissue. It has been reported that the role of CAT only appears important in concentrations of $\mathrm{H}_{2} \mathrm{O}_{2}$ higher than $10^{-6} \mathrm{M}$ [63], yet these concentrations in normal physiological conditions are rarely achieved besides an oxidative burst or over-expression of SOD [64]. According to Vernet et al. [16], CAT does not appear to be a major participant in the control of oxidative stress within the epididymis, yet other researchers $[65,66]$ have demonstrated that catalase activity was associated with low sperm quality; in the light of these reports, the higher level of CAT in adult F1:Fin rats in the present study may have a negative impact on the fertility of offspring of finasteride-treated male rats.

The copper/zinc form of SOD (SOD1) catalyzes the dismutation of $\mathrm{O}_{2}$ to generate $\mathrm{H}_{2} \mathrm{O}_{2}$ that could potentially damage the epididymis and spermatozoa [16]. Seminal SOD activity is positively associated with sperm concentration and their overall motility, whereas it is inversely associated with sperm DNA fragmentation [19]. The very high expression of SOD1 mRNA in the adult F1:Fin rats in the present study could affect epididymal sperm maturation. In light of this danger caused by SODs, the presence of the epididymal secretory form of glutathione peroxidase (GPX5) which covers the spermatozoa head is noticeable [16, 28]. It has been demonstrated that GPX5 protects cells from oxidative stress induced lipid peroxidation and DNA mutation [67], maintains sperm DNA integrity [68] and regulates the synthesis of prostaglandin, key signaling molecules needed by spermatozoa [69]. Therefore, the decrease of GPX5 in the adult F1:Fin rats observed in our study could result in inadequate spermatozoa protection and subsequent dysfunction. In the reproductive system there is also rich expression of glutathione reductase, which supports spermatogenesis and protects the sulfhydryl groups and unsaturated fatty acids of spermatozoa plasmalemma against peroxidation during epididymal maturation and storage [70]. In our study we observed a reduction in GR transcript at the end of the first month in the F1:Fin group and a level not statistically higher in mature rats than controls. Consequently, it may lead to a lesion of the plasma membrane of spermatozoa and its insufficient fluidity.

The different levels of antioxidant enzymes in the successive days of development could be correlated with postnatal formation of the blood-epididymis barrier. An electron microscopic study by Agrawal and Hoffer [71] showed gradual postnatal development of the blood-epididymis barrier with formation complete by day 21 . The various levels of antioxidant enzymes in the epididymis could be connected with the ongoing processes in the testes, such as intense cell proliferation/apoptosis to provide the proper ratio between the number of 
Sertoli and spermatogonial stem cells, blood-testis-barrier formation, and the secretory function undertake by Sertoli cells during the first wave of spermatogenesis [72-78]. Or there may be just a correlation with the changes in antioxidant levels in the testes during life, as was documented by Samanta et al. [79].

\section{Androgens as regulators of antioxidant enzymes in epididymides}

The different levels of antioxidant enzymes in the successive days of development could be correlated with the hormonal secretion of testicular Leydig cells, which change over the animal's life (plasma testosterone concentration in pubertal rats is higher than in adults) [80-82], which is in conformity with our observation. Moreover, the specific regions of the epididymis (caput, corpus, cauda) possess distinct spatially restricted gene expression profiles, ensuring suitable epididymal functions essential to the different steps of sperm maturation, where factors such as steroidal hormones can affect the pattern of gene expression [83]. It has been confirmed that some genes encoding antioxidant enzymes are androgen-dependent [24, 30-33, 35]. Our study revealed an age-dependent correlation between serum androgen concentration and various antioxidant enzyme transcription levels. These correlations when comparing F1:Control to F1:Fin rats were different. Catalase mRNA positively and moderately correlated with DHT in control rat offspring, but in finasteride-treated male rat offspring the correlation was moderate and negative for both androgens (T, DHT). Only in the F1:Control group were there strong negative correlations between GPX5 mRNA and the androgens (both T and DHT). Other enzymes' transcripts (SOD1, GR) were not linked to serum androgens concentration. Consequently, the transgenerational effect of finasteride could alter the antioxidant defense status of the epididymis.

\section{Endocrine disruptors and changes in epididymal antioxidant enzymes}

There are many reports indicating the adverse influence of endocrine disruptors $[55,56]$ such as dioxin [55], pesticides [59] or insecticides [58] with hormonal properties, on a decrease of SOD, CAT, GR and GPX activity in sperm collected from the epididymis. Significantly decreased activities of these enzymes have been documented in epididymis homogenates from bisphenol A-treated rats [84] and lindane-treated rats, which had more significant changes in the cauda than the caput or corpus regions of the organ [58]. Methoxychlor similarly decreased the activity of antioxidant en- zymes (SOD, CAT, GR, GPX) in the epididymis with respect to the regions of the organ [59]. The study by Kolasa et al. [37] demonstrated that finasteride treatment of adult rats changed the epididymal region-specific immunoexpression of antioxidant enzymes (GPX5: increase in the caput of treated rats compared to control rats; E-SOD: increase in the caput and decrease in the cauda of treated rats). Also, treatment of Wistar male rats with ethanol and atrazine showed diverse results: CAT activity in epididymal homogenates decreased, SOD and GPX activity increased [60]. The action of finasteride could be compared to that mentioned above of EDs with estrogenic/antiandrogenic activity, as according to the official brochure from the manufacturer of Propecia (Merck Sharp \& Dohme Corporation, Kenilworth, USA) [85], "mean circulating levels of testosterone and estradiol increased by approximately 15\%". Additionally, the study by Vaughan et al. [86] established that finasteride treatment ( $1 \mathrm{mg} /$ day) increased the concentration of testosterone and led to its conversion to estradiol, and finally resulted in increased levels of estrogen.

The different levels of plasma and intratesticular levels of T and DHT in control rats (F1:Control) when compared to F1:Fin animals [38] may reflect the fluctuation/oscillation of antioxidant expression in the successive days of the experiment. In general, other male reproductive toxins such as chlorpyrifos (insecticide) [87], atrazine (pesticide) [60], and nonylphenol (ED) [56], that postnatally influence an organism also caused a reduction in plasma testosterone concentration. Similarly, the inhibition of $5 \alpha$-reductase 2 activity by finasteride changed plasma androgen concentrations in finasteride-treated adult male rats [37] and in male offspring of these rats [38]. The differences in androgen levels between the F1:Fin and F1:Control groups of rats exhibit some resemblance to the results of studies which explored prenatal exposure to anti-androgenic endocrine disruptors such as flutamide [88] or vinclozolin [89] that reduced serum testosterone concentrations in adult animals. But in our data, the adult (PND 90) offspring of finasteride-treated male rats had an increased $T$ serum level and decreased DHT serum level. Anyway, there is a lot of evidence for considering the role of DHT-dependent mechanisms in controlling epididymal functions [90].

In conclusion, finasteride treatment of parental rats resulted in changes in their offspring, namely: (i) antioxidant enzyme (CAT, SOD1, GR, GPX5) expression in the epididymis at mRNA and protein levels, (ii) immunolocalization of the enzymes in epididymal epithelial cells, (iii) correlations (positive/negative/lack) between serum androgens and transcripts of antioxidant enzymes (CAT, GPX5) in finasteride-treated male offspring in comparison to controls. 
These mentioned changes could disturb the epididymal microenvironment, such as the antioxidant defense system and concentration of ROS, which are needed for correct post-testicular spermatozoa maturation.

\section{Acknowledgments}

This work was financed by the Pomeranian Medical University within the framework of "The Fund of Science Stimulation” (FSN-167-03/15).

\section{Conflict of interest}

The authors declare no conflict of interest.

\section{References}

1. Rejraji H, Sion B, Prensier G, et al. Lipid remodeling of murine epididymosomes and spermatozoa during epididymal maturation. Biol Reprod 2006; 74: 1104-13.

2. Cooper TG. Sperm maturation in the epididymis: a new look at an old problem Asian J Androl 2007; 9: 533-9.

3. Cornwall GA. New insights into epididymal biology and function. Hum Reprod Update 2009; 15: 213-27.

4. Raymond AS, Elder B, Ensslin M, Shur BD. Loss of SED1/ MFG-E8 results in altered luminal physiology in the epididymis. Mol Reprod Dev 2010; 77: 550-63.

5. Aitken RJ. The Amoroso lecture. The human spermatozoon - a cell in crisis? J Reprod Fertil 1999; 115: 1-7.

6. Aitken RJ, Baker MA. Oxidative stress and male reproductive biology. Reprod Fertil Dev 2004; 16: 581-8.

7. Hinton BT, Palladino MA. Epididymal epithelium: its contribution to the formation of a luminal fluid microenvironment. Microsc Res Tech 1995; 30: 67-81.

8. Peltola V, Huhtaniemi I, Metsa-Ketela T, Ahotupa M. Induction of lipid peroxidation during steroidogenesis in the rat testis. Endocrinology 1996; 137: 105-12.

9. Aitken RJ, Baker MA. Reactive oxygen species generation by human spermatozoa: a continuing enigma. Int J Androl 2002; 25: 191-4.

10. Garrido N, Meseguer M, Simon C, Pellicer A, Remohi J. Pro-oxidative and anti-oxidative imbalance in human semen and its relation with male fertility. Asian J Androl 2004; 6: 59-65.

11. Henkel RR. Leukocytes and oxidative stress: dilemma for sperm function and male fertility. Asian J Androl 2012; 13: 43-52.

12. Agarwal A, Makker K, Sharma R. Clinical relevance of oxidative stress in male factor infertility: an update. Am J Reprod Immunol 2008; 59: 2-11.

13. Desai N, Sabanegh E Jr, Kim T, Agarwal A. Free radical theory of aging: implications in male infertility. Urology 2010; 75: 14-9.

14. Baker MA, Aitken RJ. The importance of redox regulated pathways in sperm cell biology. Mol Cell Endocrinol 2004; 216: 47-54.

15. Lenzi A. Lipoperoxidation damage of spermatozoa polyunsaturated fatty acids (PUFA): scavenger mechanisms and possible scavenger therapies. Front Biosc 2000; 5: E1-15.

16. Vernet P, Aitken RJ, Drevet JR. Antioxidant strategies in the epididymis. Mol Cell Endocrinol 2004; 216: 31-9.

17. Cocuzza M, Sikka SC, Athayde KS, Agarwal A. Clinical relevance of oxidative stress and sperm chromatin damage in male infertility: an evidence based analysis. Int Braz J Urol 2007; 33: 603-21.
18. Agarwal A, Nallella KP, Allamaneni SS, Said TM. Role of antioxidants in treatment of male infertility: an overview of the literature. Reprod Biomed Online 2004; 8: 616-27.

19. Aitken RJ, Buckingham DW, Carreras A, Irvine DS. Superoxide dismutase in human sperm suspensions: relationship with cellular composition, oxidative stress, and sperm function. Free Radic Biol Med 1996; 21: 495-504.

20. Perry AC, Jones R, Niang LS, Jackson RM, Hall L. Genetic evidence for an androgen-regulated epididymal secretory glutathione peroxidase whose transcript does not contain a selenocysteine codon. Biochem J 1992; 285: 863-70.

21. Perry AC, Jones R, Hall L. Isolation and characterization of a rat CDNA clone encoding a secreted superoxide dismutase reveals the epididymis to be a major site of its expression. Biochem J 1993; 293: 21-5.

22. Zini A, Schlegel PN. Expression of glutathione peroxidases in the adult male rat reproductive tract. Fertil Steril 1997; 68: 689-95.

23. Zini A, Schlegel PN. Identification and characterization of antioxidant enzyme mRNAs in the rat epididymis. Int J Androl 1997; 20: 86-91.

24. Drevet JR, Lareyre JJ, Schwaab V, Vernet P, Dufaure JP. The PEA3 protein of the Ets oncogene family is a putative transcriptional modulator of the mouse epididymis-specific glutathione peroxidase gene gpx5. Mol Reprod Dev 1998; 49: 131-40.

25. Williams K, Frayne J, Hall L. Expression of extracellular glutathione peroxidase type 5 (GPX) in the rat male reproductive tract. Mol Hum Reprod 1998; 4: 841-8.

26. Williams K, Frayne J, McLaughlin EA, Hall L. Expression of extracellular superoxide oxidase in the human male teproductive tract, detected using antisera raised against a recombinant protein. Mol Hum Reprod 1998; 4: 235-42.

27. Jervis KM, Robaire B. Dynamic changes in gene expression along the rat epididymis. Biol Reprod 2001; 65: 696-703.

28. Rejraji H, Vernet P, Drevet JR. GPX5 is present in the mouse caput and cauda epididymidis lumen at three different locations. Mol Reprod Dev 2002; 63: 96-103.

29. Kaneko T, luchi Y, Kobayashi T, et al. The expression of glutathione reductase in the male reproductive system of rats supports the enzymatic basis of glutathione function in spermatogenesis. Eur J Biochem 2002; 269: 1570-8.

30. Syntin P, Dacheux JL, Dacheux F. Postnatal development and regulation of proteins secreted in the boar epididymis. Biol Reprod 1999; 61: 1622-35.

31. Rigaudiere N, Ghyselinck NB, Faure J, Dufaure JP. Regulation of the epididymal glutathione peroxidase-like protein in the mouse: dependence upon androgens and testicular factors. Mol Cell Endocrinol 1992; 89: 67-77.

32. Vernet P, Faure J, Dufaure JP, Drevet JR. Tissue and developmental distribution, dependence upon testicular factors and attachment to spermatozoa of GPX5, a murine epididymis-specific glutathione peroxidase. Mol Reprod Dev 1997; 47: 87-98.

33. Lareyre JJ, Claessens F, Rombauts W, Dufaure JP, Drevet JR. Characterization of an androgen-specific response element within the promoter of the epididymis-specific murine glutathione peroxidase 5 gene. Mol Cell Endocrinol 1997; 129: 33-46.

34. Schwaab V, Lareyre JJ, Vernet P, et al. Characterization, regulation of the expression and putative roles of two glutathione peroxidase proteins found in the mouse epididymis. J Reprod Fertil 1998; 53: 211-4.

35. Schwaab V, Faure J, Dufaure JP, Drevet JR. GPx3: the plasma-type glutathione peroxidase is expressed under 
androgenic control in the mouse epididymis and vas deferens. Mol Reprod Dev 1998; 51: 362-72.

36. Zini A, Schlegel PN. Effect of hormonal manipulation on mRNA expression of antioxidant enzymes in the rat testis. J Urol 2003; 169: 767-71.

37. Kolasa A, Marchlewicz M, Adler G, Ciechanowicz A, Głąbowski W, Wiszniewszka B. Expression of E-SOD, GPX5 mRNAs and immunoexpression of Cu/ZnSOD in epididymal epithelial cells of finasteride-treated rats. Andrologia 2008; 40: 303-11.

38. Kolasa-Wołosiuk A, Misiakiewicz-Has K, BaranowskaBosiacka I, Gutowska I, Wiszniewska B. Androgen levels and apoptosis in the testis during postnatal development of finasteride-treated male rat offspring. Folia Histoch Cytobiol 2015; 52: 236-48.

39. Kolasa-Wołosiuk A, Misiakiewicz-Has K, BaranowskaBosiacka I, et al. Connexin 43 expression in the testis during postnatal development of finasteride-treated male rat offspring. Arch Med Sci 2018; 14: 1471-9.

40. Parlaktas BS, Atilgan D, Gencten Y, et al. A pilot study of the association of manganese superoxide dismutase and glutathione peroxidase 1 single gene polymorphisms with prostate cancer and serum prostate specific antigen levels. Arch Med Sci 2015; 11: 994-1000.

41. Kolasa A, Marchlewicz M, Wenda-Rózewicka L, Wiszniewska B. Morphology of the testis and the epididymis in rats with dihydrotestosterone (DHT) deficiency. Rocz Akad Med Bialymst 2004; 49 Suppl 1: 117-9.

42. Kolasa A, Marchlewicz M, Kurzawa R, et al. The expression of inducible nitric oxide synthase (iNOS) in the testis and epididymis of rats with a dihydrotestosterone (DHT) deficiency. Cell Mol Biol Lett 2009; 14: 511-27.

43. Kolasa A, Marchlewicz M, Wenda-Różewicka L, Wiszniewska B. DHT deficiency perturbs the integrity of the rat seminiferous epithelium by disrupting tight and adherens junctions. Folia Histochem Cytobiol 2011; 49: 62-71.

44. Ashby J, Tinwell H, Odum J, Lefevre P. Natural variability and the influence of concurrent control values on the detection and interpretation of low-dose or weak endocrine toxicities. Environ Health Perspect 2004; 112: 847-53.

45. Gao W, Kearbey JD, Nair VA, et al. Comparison of the pharmacological effects of a novel selective androgen receptor modulator, the 5alpha-reductase inhibitor finasteride, and the anti androgen hydroxyl flutamide in intact rats: new approach for benign prostate hyperplasia. Endocrynology 2004; 145: 5420-8.

46. Chan SHH, Tai MH, Li ChY, Chan JYH. Reduction in molecular synthesis or enzyme activity of superoxide dismutases and catalase contributes to oxidative stress and neurogenic hypertension in spontaneously hypertensive rats. Free Radic Biol Med 2006; 40: 2028-39.

47. Iskusnykh IY, Popova TN, Agarkov AA, Pinheiro de Carvalho MA, Rejevskiy SG. Expression of glutathione peroxidase and glutathione reductase and level of free radical processes under toxic hepatitis in rats. J Toxicol 2013; 2013: 870628.

48. Goyal HO, Hutto V, Maloney MA. Effects of androgen deprivation in the goat epididymis. Acta Anat 1994, 150: 127-35.

49. Ezer N, Robaire B. Androgen regulation of epididymal structure and function. In: The Epididymis from Molecules to Clinical Practice. Robaire B, Hinton BT (eds.) Kluwer Academic/Plenum Publishers, New York 2002; 297-316.
50. Lei ZM, Zou W, Mishra S, Li X, Rao ChV. Epididimal phenotype in lutenizing hormone receptor knockout animals and its response to testosterone replacement therapy. Biol Reprod 2003; 68: 888-95.

51. Klinefelter DR, Hess R. Toxicology of the male excurrent duct and accessory sex glands. In: Reproductive and Developmental Toxicology. Korach KS (ed.). Marcel Dekker, Inc. 1998; 553-91.

52. Hess ML, Manson NH. Molecular oxygen: friend and foe. The role of the oxygen free radical system in the calcium paradox, the oxygen paradox and ischemia/reperfusion injury. J Mol Cell Cardiol 1984; 16: 969-85.

53. Greabu M, Battino M, Mohora $M$, et al. Oxygen, a paradoxical element? Rom J Intern Med 2008; 46: 125-35.

54. vom Saal FS, Cooke PS, Bauchanan DL, et al. A physiologically based approach to the study of bisphenol $A$ and other estrogenic chemicals on the size of reproductive organs, daily sperm production, and behavior. Toxicol Ind Health 1998; 14: 239-60.

55. Latchoumycandane C, Chitra KC, Mathur PP. The effect of 2,3,7,8-tetrachlorodibenzo-p-dioxin on the antioxidant system in mitochondrial and microsomal fractions of rat testis. Toxicology 2002; 171: 127-35.

56. Aly HAA, Domenech O, Banjar ZM. Effect of nonylphenol on male reproduction: analysis of rat epididymal biochemical markers and antioxidant defense enzymes. Toxicol Appl Pharmacol 2012; 261: 134-41.

57. Chitra KC, Latchoumycandane C, Mathur PP. Induction of oxidative stress by bisphenol $A$ in the epididymal sperm of rats. Toxicology 2003; 185: 119-27.

58. Chitra KC, Sujatha R, Latchoumycandane C, Mathur PP. Effect of lindane on antioxidant enzymes in epididymis and epididymal sperm of adult rats. Asian J Androl 2001; 3: 205-8.

59. Latchoumycandane C, Chitra KC, Mathur PP. The effect of methoxychlor on the epididymal antioxidant system of adult rats. Reprod Toxicol 2002; 16: 161-72.

60. Abarikwu SO, Duru QC, Chinonso OV, Njoku RC. Antioxidant enzymes activity, lipid peroxidation, oxidative damage in the testis and epididymis, and steroidogenesis in rats after co-exposure to atrazine and ethanol. Andrologia 2016; 48: 548-57.

61. Zhang Y, Calvo E, Martel C, Luu-The V, Labrie F, Tchernof $A$. Response of the adipose tissue transcriptome to dihydrotestosterone in mice. Physiol Genomics 2008; 35: 254-61.

62. Zubkova EV, Robaire B. Effect of glutathione depletion on antioxidant enzymes in the epididymis, seminal vesicles, and liver and on spermatozoa motility in the aging brown Norway rat. Biol Reprod 2004; 71: 1002-8.

63. Cohen G, Hochstein P. Glutathione peroxidase: the primary agent for the elimination of hydrogen peroxide in erythrocytes. Biochemistry 1963; 2: 1420-8.

64. Przedborski S, Jackson-Lewis V, Kostic V, Carlson E, Epstein CJ, Cadet JL. Superoxide dismutase, catalase, and glutathione peroxidase activities in copper/zinc superoxide dismutase transgenic mice. J Neurochem 1992; 58: 1760-7.

65. Kawakami E, Takemura A, Sakuma M, et al. Superoxide dismutase and catalase activities in the seminal plasma of normozoospermic and asthenozoospermic Beagles. J Vet Med Sci 2007; 69: 133-6.

66. Sabouhi S, Salehi Z, Bahadori MH, Mahdavi M. Human catalase gene polymorphism (CAT C-262T) and risk of male infertility. Andrologia 2015; 47: 97-101.

67. Taylor A, Robson A, Houghton BC, Jepson CA, Ford WC, Frayne J. Epididymal specific, selenium-independent 
GPX5 protects cells from oxidative stress-induced lipid peroxidation and DNA mutation. Hum Reprod 2013; 28: 2332-42.

68. Chabory E, Damon C, Lenoir A, et al. Epididymis seleno-independent glutathione peroxidase 5 maintains sperm DNA integrity in mice. J Clin Invest 2009; 119: 2074-85.

69. Aitken RJ, Kelly RW. Analysis of the direct effects of prostaglandins on human sperm function. J Reprod Fertil 1985; 73: 139-46.

70. Kaneko T, luchi Y, Kobayashi T, et al. The expression of glutathione reductase in the male reproductive system of rats supports the enzymatic basis of glutathione function in spermatogenesis. Eur J Biochem 2002; 269. 1570-8.

71. Agrawal A, Hoffer AP. Ultrastructural studies on the development of the blood-epididymis barrier in immature rats. J Androl 1989; 10: 425-31.

72. Clermont Y, Perey B. Quantitative study of the cell population of the seminiferous tubules in immature rats. Am J Anat 1957; 100: 241-67.

73. de Rooij DG. Proliferation and differentiation of spermatogonial stem cells. Reproduction 2001; 121: 347-54.

74. Jahnukainen K, Chrysis D, Hou M, et al. Increased apoptosis occurring during the first wave of spermatogenesis is stage-specific and primarily affects midpachytene spermatocytes in the rat testis. Biol Reprod 2004; 70: 290-6.

75. Phillips BT, Gassei K, Orwig KE. Spermatogonial stem cell regulation and spermatogenesis. Philos Trans $\mathrm{R}$ Soc Lond B Biol Sci 2010; 365: 1663-78.

76. Rodriguez I, Ody C, Araki K, Garcia I, Vassalli P. An early and massive wave of germinal cell apoptosis is required for the development of functional spermatogenesis. EMBO J 1997; 16: 2262-70.

77. Morales A, Mohamed F, Cavichia JC. Apoptosis and blood-testis barrier during the first spermatogenic wave in the pubertal rat. Anat Rec (Hoboken) 2007; 290: 206-14.

78. Russell LD, Bartke A, Goh JC. Postnatal development of the Sertoli cell barrier, tubular lumen, and cytoskeleton of Sertoli and myoid cells in the rat and their relationship to tubular fluid secretion and flow. Am J Anat 1989; 84: 179-89.

79. Samanta L, Roy A, Chainy GBN. Changes in rat testicular antioxidant defence profile as a function of age and its impairment by hexachlorocyclohexane during critical stages of maturation. Andrologia 1999; 31: 83-90.

80. Resko JA, Feder HH, Goy RW. Androgen concentrations in plasma and testis of developing rats. J Endocrinol 1968; 40: 485-91.

81. Knorr DW, Vanha-Perittual T, Lipsett MB. Structure and function of rat testis through pubescence. Endocrinology 1970; 86: 1298-304.

82. Grota LJ. Effect of age and experience on plasma testosterone. Neuroendocrynology 1971; 8: 136-43.

83. Belleannée C, Thimon V, Sullivan R. Region-specific gene expression in the epididymis. Cell Tissue Res 2012; 349: 717-31.

84. Chitra KC, Rao KR, Mathur PP. Effect of bisphenol A and co-administration of bisphenol $A$ and vitamin $C$ on epididymis of adult rats: a histological and biochemical study. Asian J Androl 2003; 5: 203-8.

85. https://dailymed.nlm.nih.gov/dailymed/archives/ fdaDrugInfo.cfm?archiveid $=52853$

86. Vaughan C, Goldstein FC, Tenover JL. Exogenous testosterone alone or with finasteride does not improve mea- surements of cognition in healthy older men with low serum testosterone. J Androl 2007; 28: 875-82.

87. Mandal TK, Das NS. Testicular gametogenic and steroidogenic activities in chlorpyrifos insecticide-treated rats: a correlation study with testicular oxidative stress and role of antioxidant enzyme defense systems in Sprague-Dawley rats. Andrologia 2012; 44: 102-15.

88. Kotula-Balak M, Hejmej A, Kopera I, Lydka M, Bilinska B. Prenatal and neonatal exposure to flutamide affects function of Leydig cells in adult boar. Domest Anim Endocrinol 2012; 42: 142-54.

89. Uzumcu M, Suzuki H, Skinner MK. Effect of the anti-androgenic endocrine disruptor vinclozolin on embryonic testis cord formation and postnatal testis development and function. Reprod Toxicol 2004; 18: 765-74.

90. Henderson NA, Cook GM, Robarie B. Effects of PNU157706, a dual 5alpha-reductase inhibitor, on gene expression in the rat epididymis. J Endocrinol 2004; 181: $245-61$. 